\title{
CAPítTLLO 8
}

\section{ÀS CRIANÇAS DO $1^{\circ}$ ANO DE 2020: UMA CARTA PARA DAQUI A ALGUNS ANOS}

Tomaz Volpi Guimarães Piestun

\section{Queridas e queridos,}

Esta carta tem um cenário: estamos em 2020, ano em que fazer escola teve de ser possível sem que as paredes da sala, a terra do quintal, fossem nosso espaço de encontro. Em 2020, fazer escola esvaziou-se de matéria, de presença, valendo-se do virtual como único meio disponível para acontecer um real. Sou professor de vocês, uma recém-chegada turma de $1^{\circ}$ ano do Fundamental, com a sensível tarefa de pautar, mobilizar e desenrolar a pauta da alfabetização como centro do jogo, mais do que em nenhum outro ano escolar que vocês tenham vivido. A maioria dos encontros que fundamentam essa nossa prática todos os anos - encontro de lápis e papel, olhos e livro, voz e ouvido, olhos e olhos, giz e lousa, mãos e mãos - está agora em xeque (para não dizer em quarentena). E, como se esses desafios fossem poucos, a frustração de expectativas que eles impuseram a todas nós, pessoas envolvidas na comunidade escolar, cresceram juntas como um desafio quase à parte da alfabetização em si. Me explico:

Hoje faz exatamente 140 dias (sim, eu fui contar) que me mandaram vir pra minha casa sem saber muito bem quando poderia sair de novo. Passado algum tempo, fui (nós fomos, não é?) entendendo melhor que seria possível sair uma vez ou outra, por motivos específicos e necessários. Passado mais tempo ainda, 
fui entendendo que, na verdade, essa história de poder sair ou não era algo que mudava a cada dia. Então, se em uma semana eu entendia mais ou menos bem o que podia e não podia fazer, na semana seguinte a regra já tinha mudado e eu não sabia direito mais. Para mim, o mais estranho era sentir que, na verdade, não tinha ninguém escrevendo essa regra: era uma regra inventada por um vírus, e nós, que não falamos língua de vírus, a tínhamos que ir descobrindo — tipo uma caça ao tesouro.

Teria sido mais legal se o vírus nos entregasse as charadas antes de o jogo começar, para que pudéssemos ir tentando adivinhar e, assim, quando começasse, já entenderíamos melhor a língua dele. Se, pelo menos, tivesse dado pra dar essa dica ao vírus antes de tudo começar... Ainda que aqui no Brasil nós tenhamos ganhado uma folguinha de uns três meses em relação a outros países - e não aproveitamos quase nada, não é?

Fato é que, quando me mandaram ir para casa, eu não falava língua de vírus, nem tinha lido as regras do jogo. Nem imaginava que, se decifrar as regras do vírus era o começo do jogo, ainda viriam muitas outras línguas e regras novas dentro desse jogo que eu também precisaria aprender. Um tanto fomos aprendendo juntos, porque nós tínhamos de inventar como propor aulas para vocês, e vocês tinham de inventar como participar delas. Engraçado que "aprender juntos" na quarentena não tem nada a ver com o "aprender juntos" que descreveria um dia de aulas na escola antes de tudo isso começar. Aquilo que mencionei no começo, dos encontros que fariam esse nosso "juntos" acontecer em um ano menos peculiar: vozes que encontram ouvidos ao lermos um texto, olhos que encontram olhos ao fazermos perguntas, nossas mãos, que se tocam mirando o papel ou uma pega de lápis, o cheiro do giz soltando pó no contato com a lousa. Percebam que só citei alguns dos muitos encontros de que nossa escola é feita, todos esses interrompidos e impossíveis na mediação que o computador faz de nossas aulas. E, ainda assim, usamos as mesmas palavras, "aprender juntos", para falar disso que não basta ser feito só por alguns de nós, mas precisa ser feito por cada um sozinho, separado do outro.

Estou pensando nessas línguas que aprendemos: línguas são fazedoras de encontros, (re)constroem nossas relações com tudo à nossa volta. Muitas línguas aprendemos sem querer, até sem poder resistir: as línguas dos cheiros das pessoas, das vozes que conhecemos, dos logotipos que associamos a marcas, das expressões faciais que associamos a sentimentos, das sensações do corpo que associamos a estados de bem ou mal-estar... Quando conheci vocês e começamos a trabalhar juntos, três anos atrás, em meio a várias línguas, uma grande e poderosa delas nos 
conectava (a língua portuguesa). Conhecê-la, no entanto, garantia muito pouco em termos das condições de possibilidade do nosso encontro, inclusive pelo fato de que muitos de vocês não passavam dos 3 anos de idade e viviam outras línguas - as do universo da brincadeira, por exemplo - com muito mais intensidade e sentido do que aquela. Aprendemos a língua dos olhares e dos toques um do outro, dos gostos de cada um, das aberturas e das perspectivas de contato, das vergonhas e das explorações, das preferências alimentares. Ao final daquele ano, vocês ganharam uma etiqueta com nome colada no banquinho que cada um usava para se sentar na roda, e isso foi um marco da disparada de vocês no aprendizado de leitura de uma língua - que, para muitos, talvez parecesse a primeira, a única, a maior de todas as línguas a se aprender na escola. Mas aos 3 anos de idade vocês já sabiam, mesmo talvez sem o saber de todo, que nem aquela língua novidadesca teria o poder de erodir o relevo de tantas leituras aprendidas e exercitadas por vocês em tantas outras línguas antes daquela. Vocês já eram poliglotas, com repertório o bastante para ensinar uma legião de outros poliglotas que viriam depois de vocês e, ainda assim, lhes cabia o aprendizado de algo aparentemente tão inofensivo como a leitura do nome próprio.

Nestes tempos de distanciamento físico, para além daquele tanto de línguas que pudemos aprender juntos, outro tanto tive de aprender por minha conta. A preciosa (mas nem sempre disponível) ajuda solidária de outros adultos que viviam a mesma fragilidade me fez enxergar um fato que eu, grande entusiasta de línguas, quase ignorava. Um fato que me fez ir e voltar no tempo em pensamento e me botou diante de mim, com 3 anos de idade, ali naquele mesmo chão onde conheci vocês: vestindo o mesmo uniforme laranja sujo de tinta e terra, rodando pelo espaço à procura do banco com minha foto e meu nome escrito, eu, também, era um poliglota com línguas por aprender. No entanto, agora, menos pimposo do que vocês procurando pelos nomes nos bancos, eu era um poliglota recém-informado de que boa parte de tudo aquilo que eu passara milhares e milhares de dias aprendendo tinha sido indefinidamente cancelado. Pegar a bicicleta para o trabalho? Cancelado. Chamar amigos para inaugurar um jogo novo de cartas? Cancelado. Ir à feira para pegar milho e, de quebra, ainda comer um pastel com caldo de cana? Canceladíssimo. Todas as línguas que se esticassem para fora dos limites do meu apartamento estavam banidas, sob pena, inclusive, de alimentarem uma ingênua esperança de que aquilo não duraria mais além do tempo de uma massinha ressecar fora do pote. Desde a chegada do vírus, já foram incontáveis massinhas ressecadas... 
Hoje pensando, se não cuido, me parece quase banal essa ideia de que há um zilhão de línguas por aprender. Digo isso porque não foi do nada: veio em um percurso que, como a alfabetização, só percebi quando já tinha muito tempo de começado - por efeito de um encontro com a Laura, antiga professora de vocês, que me abriu o olhar para essas línguas todas. E, em boa medida, fez isso com vocês também. Ela foi uma grande parceira que encontrei nestes tempos de acontecimentos tão insólitos. Também como a alfabetização, o que pensava antes desse percurso todo é algo que me escapa: por isso, se não cuido, quase penso que sempre foi e seria assim mesmo.

Outra parceria, agora com um amigo muito querido de tempos de escola, me tirou de órbita e me trouxe aqui, para escrever a vocês: foi um desencontro de línguas com ele. Não nos falávamos fazia, talvez, uns dois anos, quando recebi algumas mensagens escritas no meu telefone. Ele tinha encontrado em casa umas cartas que trocamos ao final do $7^{\circ}$ ano, quando eu tinha 12 , como parte de uma atividade de despedida antes das férias, e me mandou fotos delas. Logo reconheci aquelas cartas e respondi a ele muito feliz. Começamos a trocar mensagens escritas, nos atualizando sobre a vida um do outro, depois passando a mensagens de áudios - que são uma certa língua com certas regras que eu mais ou menos já conhecia antes de ter que ficar em casa. Ele enviou várias delas em sequência, somando vários minutos de fala. Eu as vi, mas nem as ouvi, nem respondi. Fiquei me perguntando por que, se em vários momentos do meu dia eu passava vinte, trinta, quarenta minutos conversando com alguém ao vivo ou pelo computador, eu sentia dificuldade em tirar quinte minutos para ouvir essas mensagens e responder.

Com algum tempo, fui entendendo melhor: tinha a ver com essa língua das mensagens de áudio e suas regras que eu achava que conhecia bem o bastante, mas, na verdade, ainda não entendia tão bem assim. Levei algum tempo para poder entender melhor, ao ponto de hoje, aqui sentado no meu quarto, eu sentir que era momento de responder a ele. Mas também não foi só isso; algo mais aconteceu: ouvir o que diziam as mensagens dele abriu em mim a percepção de outras línguas que eu também estou aprendendo e não me dava conta. Foram elas que me trouxeram para cá, para escrever a vocês. É capaz que vocês me achem bobo por isso, mas confesso que eu sentia medo de abrir aquelas mensagens dele. Medo de não saber como reagir àquilo, de fazer algo que pudesse deixar meu amigo triste, de ele achar que não entendo bem essa língua de mensagens gravadas pelo telefone.

A verdade é que eu não entendo tão bem mesmo, e os fatos falam um pouco por si, não é? Talvez, se um tempo atrás alguém tivesse me dito algo como "calma, está tudo bem você não saber! Peça ajuda, tente pensar a partir do que você já 
conhece. Tem muito disso que você já sabe...”, eu arriscaria mesmo com medo e veria, depois, que a pior coisa que poderia acontecer seria ele não me entender e eu ter de me explicar de novo. E pronto. Mas, no meu caso, isso nem aconteceu: eu só tive medo, não fiz nada com isso e deixei a coisa de lado por um bom tempo.

Pensem em alguma aula nossa de trabalho com leitura e escrita. Dessas em que precisamos escrever juntos uma palavra e o jeito de fazer isso é justamente o que faz nossa discussão acontecer: o "Tân" de "Mata Atântica" é com "c" ou com " $t$ "? Esse "a" tem algum chapeuzinho ou risquinho em cima para mudar o som? Precisa mesmo desse " $n$ " entre o "a" e o " $t$ "? Mas é "Atântica" ou "Atântida"? Ninguém nem chegou a mencionar que também podia caber um "l" ali no meio entre o " $t$ " e o "a". Em meio a todas essas perguntas, perguntamos a cada um de vocês como escrever a palavra. As propostas eram variadas. Havia quem nem propusesse nada, mesmo tendo sido nominalmente convidado: "faz do jeito que você acha que é...”. Nessa história com meu amigo, me senti exatamente como quem, quando convidado, não faz proposta nenhuma, fica sem falar, como se não pensasse em nada - porque sente que ainda não sabe falar ou escrever essa língua direito.

Mas não sabe mesmo? Essa conclusão é óbvia demais: eu não sei escrever, então não vou escrever. Como alguém que não sabe fazer algo poderia ir lá fazer? Alguns de vocês me fazem essa pergunta quase ofendidos, como se eu não soubesse que é óbvio que alguém que não sabe não faz e pronto. Quando abri as mensagens do meu amigo, um pouco do meu espanto era essa obviedade desmoronando na minha cabeça e eu provo, a quem me desafiar, que eu já sabia o que precisava saber para poder não deixar aquela situação sem resposta. Do mesmo jeito que todo mundo do nosso grupo, todo mundo mesmo, sabe o suficiente para dizer como escrever o nome daquele tal bioma que não sai das nossas conversas.

Isso me fez pensar: para saber algo, precisamos saber e não saber ao mesmo tempo. Saber que não sabemos, que temos algo novo por saber, que se aprende fazendo e que, ao fazer, produz outras coisas que não sabemos. Tem gente que não sabe e não sente medo nenhum com isso, porque não sabe que não sabe - ou talvez porque trate o não saber como algo que não paralisa. Esse também é um baita desafio para sustentar, porque o mesmo medo que faz não sair nenhuma escrita e nenhuma resposta é o medo que precisa fazer sair alguma resposta. Tem que ser muito corajoso para sentir medo uma vez e poder sentir de novo, o medo faz parte de como lidamos com esse não saber, medo de errar. No começo do ano, aquela mesma discussão da escrita que tivemos talvez terminasse com uma resposta parecida com "Maa Aica" para "Mata Atlântica", sentindo muito 
menos medo do que hoje, quando ficamos com a resposta "Mata Aclãntida" - esta muito mais próxima da escrita convencional e representando todos os sons que ouvimos nessas duas palavras. Uma grande professora de professores, Irandé Antunes (2009), constata e questiona as relações em sala de aula atravessadas fortemente pela expectativa do erro. Um aluno que vai errar, um professor que apontará esses erros e os corrigirá. Uma comunidade escolar que espera de aluno e professor o rastreamento exaustivo de todos os erros. Frente a um ideal de como seria o certo, a expectativa e o medo de que haja erros, como se fosse preferível não errar - e como se haver um ideal fosse menos questionável do que qualquer iniciativa que o frustrasse.

Do alto dos meus 20 e tantos anos, adulto, formado em faculdade, respeitado e cobrado por toda a gente como alguém capaz de cumprir com um monte de deveres complicadíssimos, eu percebi, com meu amigo, que ainda precisava aprender a falar e a escrever. Não naquela língua que aprendemos a chamar de "a" língua, assim, com artigo definido, como se fosse a primeira, a maior e a única língua que há para ser aprendida. Senti na pele a existência de muitas, incontáveis línguas, me lambendo por todos os lados. Eu, assustado, nem tinha visto que elas estavam lá fazia tanto tempo. E quantas não são as línguas que vamos desaprendendo ou abandonando ao nos tornarmos adultos? Lembro de um professor que dizia como uma das regras das línguas do mundo dos adultos é aceitar certas coisas do jeito que estão e não fazer perguntas, como uma máquina que executa o que tem de executar e pronto. Com o passar dos anos de uma pessoa, usar as línguas em forma de pergunta, muitas vezes, acaba sendo motivo de vergonha ou parecendo resistência ao crescimento. A própria língua portuguesa que, no começo da vida, vocês nem conheciam (e nem por isso deixavam de falar e ser compreendidos por tantas outras línguas), tornou-se um dos principais meios para falarem entre vocês, conosco e com o mundo. Vocês conseguem pensar em algumas línguas que usam muito menos hoje, quando leem esta carta, ou que deixaram de usar quando tinham 6,7 anos de vida? Talvez essa já seja uma pergunta não muito segura para um adulto fazer sem correr o risco de passar vergonha aos olhos de outros adultos que já não fazem mais perguntas... Aqui me ocorre uma passagem de outro professor, Jorge Larrosa (2019), sobre leituras e lições. Ele defende que

$\mathrm{Na}$ leitura da lição não se busca o que o texto sabe, mas o que o texto pensa. Ou seja, o que o texto leva a pensar. Por isso, depois da leitura, o importante não é que nós saibamos do texto o que nós pensamos do texto, mas o que - com o texto, ou contra o texto ou a partir do texto - nós sejamos capazes de pensar. (p. 177) 
Aprendemos um monte de regras - que, juntas e poderosas, chamamos de línguas - porque é algo que passamos a compartilhar, que nos conecta, nos comunica e nos aproxima. Quando falei sobre o ano em que nos conhecemos, falei de um monte de línguas que foram, como fios, costurando a teia do nosso encontro. Aprender a ler, para nós, foi abrir um canal com o desconhecido, muito além daquela história de juntar palavras, frases, parágrafos... entre nós, a conversa fluía sem ninguém nem pensar em sílaba. De repente, tínhamos passado a outros territórios, girado nossas órbitas, e as línguas se tornaram pauta urgente de aprendizado, tanto para os adultos como para vocês!

Se língua é relação, é contato, o medo de errar na escrita diz de algo que se antecipa do encontro com o outro: o ideal de que falei antes, que ensejará medos por estabelecer o certo e esperar o erro. Vejo pontes entre alguns dos nossos medos, até medos que os pais e as mães de vocês me trazem, talvez sem nem perceber, e penso, agora, que todos eles, de alguma forma, mobilizam o movimento de aprender. Medo de não ter controle, medo de ter de sustentar e não suportar, medo de não estar certo, medo de sentir que o erro é uma perda de tempo e que não temos mais tempo - sendo que, quando nos foi tirado quase tudo pelo jogo do vírus, uma das pouquíssimas coisas que ganhamos foi pensar o tempo. Sem medo, teríamos cometido erros talvez irremediáveis: sem o medo de nada mudar, agora, ficaríamos entregues a um vírus que já mata pelo enigma.

O medo não é evitável e também não é indesejável, assim como o movimento das línguas não é garantido: o medo pede tempo para ser vivido e se transformar - ou fazer transformar algo - para além de si mesmo. Até uns 10 anos de idade, eu tinha muito medo do escuro, mesmo em casa. Se precisasse levantar durante a noite, corria com o dedo como um vírus espirrado entre os interruptores. Hoje, gosto muito do escuro e, quando posso, passo longos períodos sem acender nada. Há uma tranquilidade e uma precisão sensorial na experiência do escuro que descobri ao dobrar meu medo, ao fazê-lo mudar de trajetória. Mas isso levou tempo (no meu caso, foram vários anos), um tempo que ninguém antes poderia ter previsto, vivido e explorado em companhia com o medo até algo ser inventado: novas relações de curiosidade e interesse que desenvolvi com o escuro. Sinto no percurso de vocês e nos medos que trazem - vocês e suas famílias - a oportunidade para um tempo de explorar, de dobrar intenções e desejos, agenciando, com o medo, ramificações de novas línguas.

Aqui faz diferença uma proposta educativa que convoca vocês no centro de seu próprio processo, como diriam as professoras Emilia Ferreiro e Ana Teberosky (1999): o pensamento é de vocês, as hipóteses e os traços no papel também serão, 
necessariamente, para que explorem essa companhia do medo e façam dele as línguas novas que aprenderão. Propor uma sustentação para o medo que rompa com o erro-falta em relação a um ideal: o medo é força desse processo. O professor Larrosa, que já citei, fala dessas línguas ao dizer da leitura:

Ler é levar o texto ao seu extremo, ao seu limite, ao espaço em branco onde se abre a possibilidade de escrever. E, por isso, o aprender da leitura dá, às vezes, a impressão de que não se aprendeu nada. Se o ensinar é dar um saber já elaborado, aquele que ensina a ler não dá nada porque o texto não dá nada que, como o saber, possa ser armazenado e apropriado. O texto só deixa escrever. (p. 182)

Ainda quero poder dizer isso aos pais e às mães de vocês, quando vierem, bravos de medo, perguntar por que vocês "ainda não sabem escrever": a língua do vírus, das mensagens de áudio, da fauna da Mata Atlântica, de conviver com as pessoas de casa por tanto tempo, todas essas são línguas que eles, vocês e nós temos por aprender. Uma dessas línguas é só mais uma dentre milhares que começaremos a desvendar e, quando talvez dissermos que aprendemos, estaremos enfatizando o movimento que não paralisa, mas mantém e inspira o percurso. $\mathrm{O}$ medo que nos fará aprender é o mesmo medo que não nos permitiria nada disso.

Um beijo entoado em muitas línguas,

Tomaz

\section{REFERÊNCIAS}

Antunes, I. (2009). Ensino de língua portuguesa: repercussões educacionais, políticas e socioeconômicas. Conjectura, Caxias do Sul, v. 14, n. 2, pp. 231-240.

Ferreiro, E. \& Teberosky, A. (1999). Psicogênese da língua escrita. Trad. Diana Myrian Lichtenstein et al. Porto Alegre: Artmed.

Larrosa, J. (2019). Sobre a lição ou do ensinar e do aprender na amizade e na liberdade. Pedagogia profana: danças, piruetas e mascaradas (pp. 173-183). 6. ed. Belo Horizonte: Autêntica. 